\title{
BILLER, Thomas, METZ, Bernhard, Der spätromanische Burgenbau im Elsaß (1200-1250)
}

\section{Olivier Bruand}

\section{OpenEdition \\ Journals}

Édition électronique

URL : http://journals.openedition.org/ifha/537

DOI : $10.4000 /$ ifha. 537

ISSN : 2198-8943

Éditeur

IFRA - Institut franco-allemand (sciences historiques et sociales)

\section{Référence électronique}

Olivier Bruand, «BILLER, Thomas, METZ, Bernhard, Der spätromanische Burgenbau im Elsaß (1200-1250)

», Revue de l'IFHA [En ligne], Date de recension, mis en ligne le 01 janvier 2007, consulté le 22

septembre 2020. URL : http://journals.openedition.org/ifha/537 ; DOI : https://doi.org/10.4000/ifha.

537

Ce document a été généré automatiquement le 22 septembre 2020

(CIFHA 


\title{
BILLER, Thomas, METZ, Bernhard, Der spätromanische Burgenbau im Elsa $\beta(1200-1250)$
}

\author{
Olivier Bruand
}

Cet ouvrage est le deuxième d'une série qui a pour ambition d'étudier tous les châteaux d'Alsace et il ne traite que de la première moitié du XIIIe s., encore considérée comme ressortissant au roman tardif. Cette classification, à première vue arbitraire, repose en fait sur l'apparition des nouvelles formes d'ouverture gothiques dans les constructions civiles qui ne se répandent réellement dans la région qu'au-delà de 1250.Avant de se lancer dans un relevé des châteaux ou de ce qu'il en reste, les deux auteurs commencent par un exposé d'une trentaine de pages sur l'histoire de l'Alsace de l'époque pour qu'on puisse insérer les constructions dans leur contexte, puis il poursuivent par une étude beaucoup plus fouillée (150 pages) des constructions, envisageant les techniques et les plans sous tous leurs aspects : formes des enceintes, tours, ouvrages de défense et bâtiments d'habitation, appareil, ornementation des ouvertures, charpentes, toitures, installations de chauffage sont tour à tour présentés, avant un résumé des acquis. La suite de l'ouvrage est consacré à des monographies qui envisagent en détail trente châteaux, en en donnant systématiquement l'historique, les phases de construction et le plan.

Cet ouvrage, très utile pour les castellologues, apporte quelques constatations marquantes. Si dans l'empire on a alors érigé de nombreux châteaux, l'Alsace se caractérise par des constructions particulièrement soignées qui ne répondent pas pour autant à un modèle systématique, mais montrent une solide capacité d'adaptation tant pour les sites choisis que pour les plans adoptés, au point de faire de l'Alsace du XIIIe s. un région qui connaît un âge d'or du château, qui accompagne l'expansion générale. Certaines régions comme les Vosges du nord, un peu délaissées, en profitent d'ailleurs pour se couvrir de nouvelles constructions qui sont encore aujourd'hui des points d'attraction pour le voyageur de passage. Le lecteur curieux regardera ainsi d'un oeil 
neuf les ruines des forteresses qui rappellent une des plus belles pages de l'histoire de l'Alsace.

Olivier BRUAND (Université Blaise-Pascal - Clermont-Ferrand II) 